\title{
IMPACTOS DA CONVERSÃO DE USO E MANEJO DO SOLO DO CERRADO UTILIZANDO DADOS DE CARBONO TOTAL E ISOTÓPICO
}

\author{
Thalita Mendes Resende* \\ Vania Rosolen**
}

\begin{abstract}
Resumo: A mesorregião do Triângulo Mineiro/Alto Paranaíba recoberta originalmente pela vegetação de Cerrado vem sendo fortemente desmatada por ser uma área pioneira de expansão do agronegócio. Dentre as várias modificações ambientais relacionadas ao desmatamento destacamse a erosão e os desequilíbrios nos estoques e na natureza das fontes de carbono. Resultados das análises de carbono total (Ctotal) e carbono isotópico $\left(\delta^{13} \mathrm{C}\right)$ de quatro categorias de uso remanescente de cerrado arbóreo, rotação de soja e milho em sistema de plantio direto, pastagem manejada e pastagem degradada - revelaram que a conversão de uso e manejo provocou mudanças importantes na natureza e no teor do carbono do solo. Os resultados apresentados podem servir como importantes indicadores de impactos ambientais quando ecossistemas naturais são convertidos em sistemas agropecuários sem adoção de manejo adequado.
\end{abstract}

Palavras-chave: Cerrado; Carbono total e isotópico; Matéria orgânica do solo; Qualidade do solo; Uso e manejo da terra.

\section{IMPACTS OF CONVERSION OF USE AND SOIL MANAGEMENT FROM CERRADO, USING TOTAL CARBON AND ISOTOPIC DATA}

\begin{abstract}
The middle region of Minas Gerais / High Paranaíba originally covered by Cerrado vegetation has been heavily deforested area for being a pioneer expansion of agribusiness. Among the various environmental changes related to deforestation include soil erosion and imbalances in stocks and the nature of carbon sources. Results of analysis of total carbon (Ctotal) and carbon isotope $\left(\delta^{13} \mathrm{C}\right)$ of four categories of use - remnant of cerrado tree, rotation of soybeans and corn in no-tillage, pasture and degraded pasture managed - revealed that the conversion of use and management led to important changes in the nature and content of the soil carbon. The results presented can serve as important indicators of environmental impacts when natural ecosystems are converted into agricultural systems without the adoption of appropriate management.
\end{abstract}

Key Words: Cerrado; and Total carbon isotope; Soil organic matter, soil quality, land use and management.

\section{Introdução}

Os ambientes do Cerrado são modificados pela conversão do uso e manejo da terra. Originalmente a área recoberta com Cerrado ocupava cerca de 2 milhões de $\mathrm{km}^{2}$, se caracterizando como o segundo maior bioma brasileiro, seguido da floresta amazônica (floresta tropical úmida). A ocupação do Cerrado brasileiro iniciou-se na década de 1930, inserida em um projeto de integração nacional, e tornou-se área prioritária para expansão da fronteira agrícola e do agronegócio a partir da década de 1970 com o início do período da modernização da agricultura brasileira, fruto de política governamental, pautada nos usos intensivos do solo, máquinas e insumos agrícolas

\footnotetext{
* Doutoranda no Programa de Pós Graduação em Geografia da Universidade Federal de Uberlândia (UFU). Email: thalitamresende@yahoo.com.br

** Profa. Dra. do Instituto de Geografia da Universidade Federal de Uberlândia (UFU). E-mail: vrosolen@ig.ufu.br
} 
(WANIEZ, 1992; BALBINO et al., 2002; BROSSARD; LÓPEZ-HERNÁNDEZ， 2005). Imensas áreas de vegetação original foram e continuam sendo desmatadas para dar espaço às monoculturas de grãos (soja e milho, principalmente), algodão, pastagens manejadas associadas com pastagens degradadas, implantação de florestas homogêneas para produção de carvão e celulose e, nos últimos anos, a expansão da cana-de-açúcar, em muitos casos na forma do monocultivo. De acordo com Lopes (1996) metade do Cerrado é composto por terras potencialmente aráveis e dois terços podem ser incorporados como sistemas agrícolas.

o Cerrado se desenvolve em condições de clima tropical com dois períodos de contrastes pluviométricos: a precipitação média anual pode variar de $400 \mathrm{~mm}$ a $2200 \mathrm{~mm}$ (SILVA et al., 2008), concentrada no período chuvoso entre os meses de outubro a abril. Os outros meses caracterizam o período seco nos quais praticamente não há chuvas. As temperaturas aumentam no sentido sul-norte do Bioma com variações médias das temperaturas máximas anuais entre 24 e $33^{\circ} \mathrm{C}$ e das temperaturas mínimas de 14 a $23^{\circ} \mathrm{C}$ (SILVA et al., 2008). Os solos tropicais lateríticos representados por Latossolos, Neossolos Quartzarênicos e Argissolos recobrem aproximadamente $75 \%$ do Bioma (REATTO et al., 2008). São solos fortemente lixiviados, dessaturados, ácidos $(\mathrm{pH}$ entre 4,0-5,5), com alta concentração de Al trocável e constituídos por argila de baixa atividade. A composição mineralógica comum associa caolinita, gibbsita, hematita e goethita e quartzo residual (MACEDO; BRYANT, 1987), cujos teores variam de acordo com a litologia e posição topográfica (VOLKOFF, 1985; CURI; FRANZMEIER, 1984). Os solos do Cerrado são extremamente frágeis e a erosão superficial ou em sulcos se constitui em um dos maiores problemas ambientais. Apesar de os Latossolos do Cerrado apresentarem microestrutura muito estável, sua macroestrutura é frágil e pouco desenvolvida e, quando presente, é subangular à grumosa (BALBINO et al., 2002).

Em virtude da rápida conversão da vegetação original em sistemas agrícolas, atualmente apenas $51,54 \%$ ou 1.051 .182 $\mathrm{km}^{2}$ compõem as áreas de remanescentes da vegetação original do bioma e, apenas 5,2\% da área total está protegida sob a forma de alguma política de conservação (MMA, 2010). A taxa anual de conversão do uso do solo entre os anos de 1999 e 2005 foi de 1,55\% (JEPSON, 2005). Dentre as várias modificações ambientais relacionadas ao desmatamento do Cerrado destacam-se a erosão, os desequilíbrios nos estoques de carbono (KLINK; MACHADO, 2005), na natureza das fontes de carbono (BALESDENT et al., 2000) e na redução do carbono ligado à biomassa e a matéria orgânica do solo (MOS) (LAL, 2003; EGOH et al., 2009).

O cenário atual reflete em grande parte a expansão agrícola, pautada na produção em larga escala de monoculturas, nas formas de plantio convencional e, após 1990, a substituição parcial e crescente desta prática de manejo em sistema de plantio direto. Estima-se que hoje a área cultivada por este sistema no Cerrado seja de aproximadamente 8 milhões de hectares (JANTÁLIA et al., 2007). Estudos focando aumento ou diminuição do teor de MOS como resultado desta prática de manejo em relação ao Cerrado nativo apontaram tanto para a conservação do carbono do solo (DA SILVA et al., 1994; LAL, 2002; DA SILVA et al., 2004; JANTÁLIA et al., 2007) quanto para diferenças pouco expressivas uma vez que fatores como a textura e mineralogia interferiram diretamente no acúmulo de 
carbono (FREITAS et al., 2000; BAYER et al., 2006; MARCHÃO et al., 2009).

Em relação à conversão do uso do solo em pastagens, a baixa produtividade das pastagens degradadas, ou seja, aquelas formadas após o corte e a queima do Cerrado e que, em virtude de limitações climáticas e edáficas são de baixa qualidade e quantidade, estimulou a introdução de pastagens com espécies vegetais africanas (Brachiária, Panicum e Andropogon) mais produtivas e com maior potencial de aumento do estoque de carbono no solo (SAVIDAN et al., 1985; BALBINO et al., 2002; CERRI et al., 2003; MARCHÃO et al., 2009). Quando não manejadas adequadamente as pastagens do cerrado formam uma cobertura vegetal descontínua que expõe a superfície do solo. Nestes casos, especialmente quando se trata de solos arenosos, há perceptível perda da fase argilosa e aumento relativo da fração areia na forma de grãos de quartzo lavados e soltos.

Nesse sentido, o objetivo deste artigo foi avaliar as mudanças na natureza $\left(\delta^{13} \mathrm{C}\right)$ e quantidade (Ctotal) do carbono do solo após 30 anos de conversão da vegetação de Cerrado denso em duas áreas de pastagens classificadas como degradada e manejada e em uma área de plantio de soja rotação com milho sob sistema de plantio direto visando comparar a influência do uso do solo na dinâmica da matéria orgânica.

\section{MATERIAL E MÉTODOS}

\section{Localização da área}

As amostras de solo foram coletadas na microbacia do Ribeirão Bom Jardim, situada na mesorregião do Triângulo Mineiro/Alto Paranaíba, nas porções Sul do município de Uberlândia e Norte do município de Uberaba, Estado de Minas Gerais (Brasil), entre as coordenadas 18058 '00" - 19020'30" de latitude Sul e 48004'00"- 48018 '00" de longitude Oeste (Figura 1). A microbacia é recoberta originalmente pela vegetação de Cerrado.

O clima da região é o tropical, caracterizado pela alternância de estações úmidas e secas, por influência sazonal de massas de ar. A precipitação média anual é de 1.550 milímetros e a temperatura média anual é de $22^{\circ} \mathrm{C}$ (ROSA et al., 1991). O relevo é plano a suave ondulado, com declividades inferiores a 5\%, predominado as vertentes convexas, sendo que próximo aos canais fluviais, ocorre uma ruptura de declive associada à presença de crostas ferruginosas. Os solos predominantes são representados por Latossolo Vermelho Distrófico e Latossolo Vermelho-Amarelo Distrófico, com a presença de Plintossolo Pétrico, Neossolo, Flúvico Tb distrófico, Neossolo Quartzarênico e Gleissolo nas áreas de veredas (BRITO, 2001).

A partir da análise do uso do solo na microbacia por meio de imagens de satélite foram escolhidas 4 áreas com diferentes categorias de uso para coleta das amostras (Figura 2). O ponto de coleta 1 corresponde a uma área de remanescente de Cerrado Arbóreo Denso (Cerradão) sobre Latossolo. O ponto de coleta 2 trata-se de uma área com plantio de soja rotação com milho em sistema de plantio direto sobre Latossolo. O ponto de coleta 3 foi uma área experimental do projeto CIAT - Centro Internacional de Agricultura Tropical da Embrapa (Empresa Brasileira de Pesquisa Agropecuária) que entre 1995 a 2005 realizou pesquisas sobre melhoramento de forrageiras do gênero Brachiaria. Esta área, denominada de Pastagem Manejada, é adubada e, a cada três anos, é fertilizada com esterco de peru e feita a correção do solo com calagem quando necessário. A gramínea cultivada é a Bachiaria e recobre solo do tipo Latossolo. O ponto de coleta 4 é uma pastagem degradada 
formada após o corte e queima do cerrado e é classificada como degradada por nunca ter sido manejada e apresentar cobertura vegetal descontínua com superfície do solo exposto. O solo é o Latossolo.

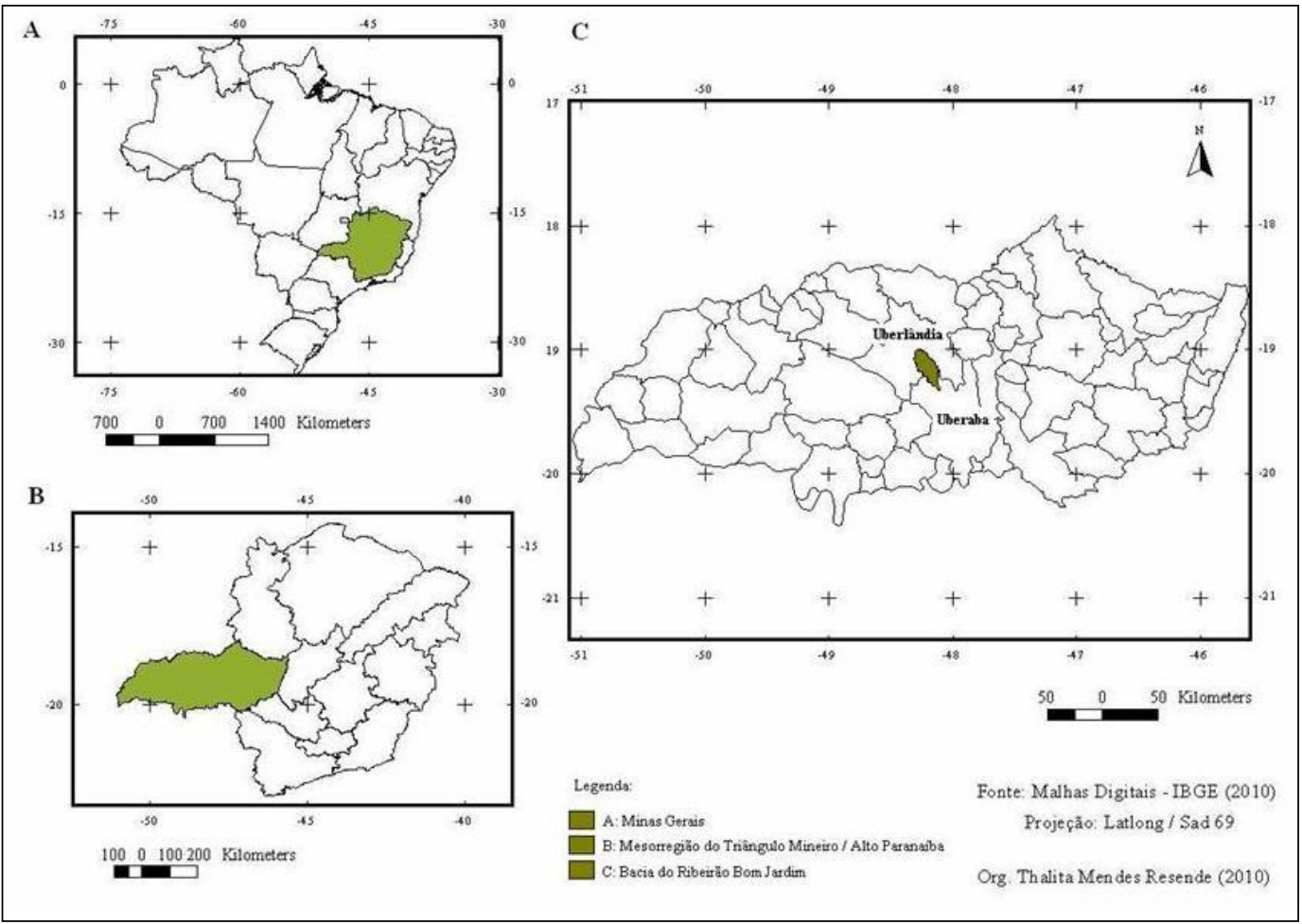

Figura 1: Localização da Bacia do Ribeirão Bom Jardim nos municípios de Uberlândia e Uberaba, Estado de Minas Gerais, Brasil.

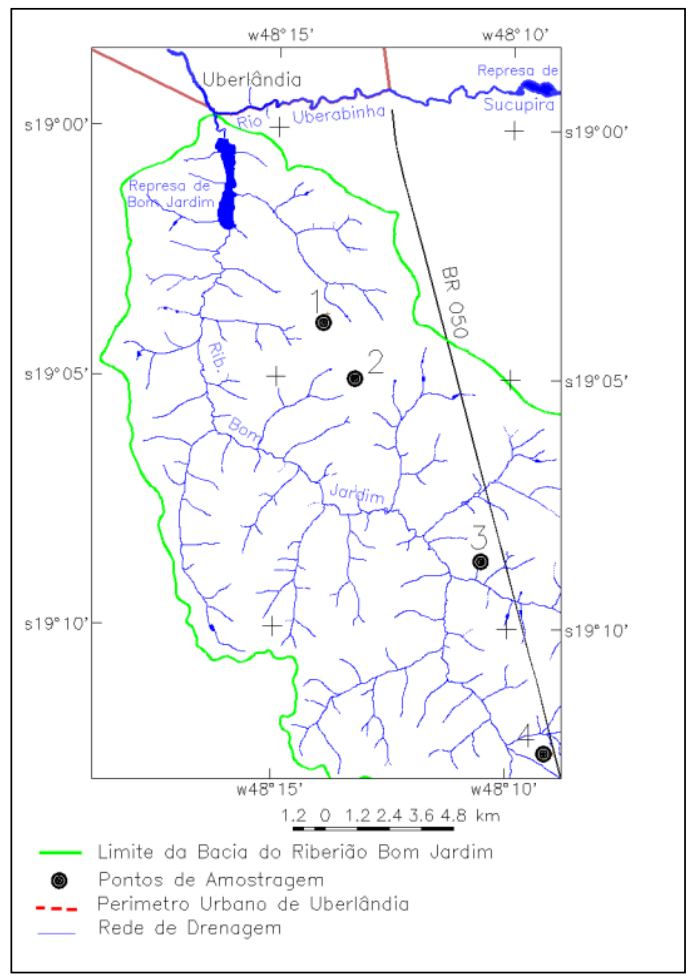

Figura 2: Mapa de Localização dos pontos amostrais na bacia do Ribeirão Bom Jardim, municípios de Uberlândia (pontos 1, 2 e 3) e município de Uberaba (ponto 4). 


\section{Coleta das amostras no campo}

As amostras foram coletadas por meio da abertura de trincheiras e em duas profundidades: na superfície entre 0 e $10 \mathrm{~cm}$ e em subsuperfície entre 20 e $30 \mathrm{~cm}$. A escolha das profundidades deveu-se ao fato de que os maiores teores de carbono orgânico encontram-se estocados na superfície do solo e que o desflorestamento e perda por mineralização se refletirão de forma mais rápida e acentuada nestas camadas (BERNOUX et al., 2002).

Em cada ponto foram coletadas três amostras de solo nas duas profundidades mencionadas o que corresponde a um total de seis amostras para cada categoria de uso. Considerando que em todas as áreas de coleta a topografia foi similar, as amostras foram coletadas nas posições topográficas de meia encosta com o objetivo de minimizar a influência topográfica e de drenagem do solo. Após a coleta, as amostras foram secadas inicialmente em condições ambientais de laboratório e, posteriormente, colocadas em estufa com temperatura de $30^{\circ} \mathrm{C}$ até atingir peso constante. Em seguida foram destorroadas, homogeneizadas e passadas em peneira de $2 \mathrm{~mm}$ para obter a fração terra fina.

\section{Análises de laboratório}

\section{Análise Granulométrica}

A análise granulométrica foi realizada segundo o método de peneiramento e pipetagem em frações padronizadas por Atteberg (areia, silte e argila) proposto no Manual de Métodos de Análise de solo (EMBRAPA, 1997). Este método baseia-se na velocidade de queda das partículas que compõem o solo. A separação entre areia grossa e areia fina foi feita por peneiramento com abertura de malha de 0,210mm (areia grossa) e $0,053 \mathrm{~mm}$ (areia fina). A porcentagem da fração silte foi obtida pela diferença entre a amostra total e a soma das frações areia e argila. Todas as frações foram secadas em estufa a $100^{\circ} \mathrm{C}$ e pesadas com aproximação de $0,01 \mathrm{~g}$ para areia grossa e areia fina e de 0,0001 g para a fração argila.

\section{Determinação do carbono orgânico total (Ctotal) e da natureza do carbono $\left(\delta^{13} \mathrm{C}\right)$}

Para determinação do teor (Ctotal) e natureza $\left(\delta^{13} \mathrm{C}\right)$ do carbono orgânico, as amostras de solo foram secas a $60^{\circ} \mathrm{C}$ até peso constante. Raízes e outros resíduos vegetais foram removidos por catação e peneiramento. Qualquer material vegetal remanescente foi removido por flotação em $\mathrm{HCl}$ 0,01 M e, posteriormente, peneiramento em $210 \mu \mathrm{m}$. O carbono isotópico $\left(\delta^{13} \mathrm{C}\right)$ e o carbono orgânico total (Ctotal) foram determinados usando um analisador Carlo Erba Analyser CHN-1110, acoplado a um espectrômetro de massa Optima Thermo Finnigan, Plus Delta. As incertezas analíticas variaram em média $0,3-0,5 \%$. Os teores de carbono orgânico total foram expressos em gramas por quilo $\left(\mathrm{g} \mathrm{kg}^{-1}\right)$ de solo seco e do carbono isotópico em $\delta^{13} \mathrm{C} \%$. O padrão usado na determinação do $\delta^{13} \mathrm{C}$ é o PDB, um carbonato (Belemnita americana) da formação Pee Dee da Carolina do Sul (EUA). A composição isotópica média do ${ }^{13} \mathrm{C}$ da matéria orgânica do solo reflete a vegetação ou sucessão de vegetações que a produziram (DEINES, 1980).

\section{RESULTADOS E DISCUSSÕES}

\section{Histórico de conversão do uso do solo}

O mapeamento da evolução do uso do solo de 1964 a 1999 foi realizado por Brito (2001) e o uso atual foi identificado por imagens de satélite e reconhecimento de campo (Tabela 1). No ano de 1964, Cerrado original predominava em todas as áreas 
deste estudo. Em 1979, os Pontos 1 e 4 se mantiveram como Cerrado, o Ponto 2 foi convertido em reflorestamento de pinus e o Ponto 3 em área agrícola com plantio de soja, seguindo a tendência da expansão da fronteira agrícola. No ano de 1989, a conversão foi intensificada e a maior parte da vegetação original da microbacia foi alterada. No Ponto 2 permaneceu o reflorestamento, no Ponto 3 a agricultura de soja e no Ponto 4 ocorreu a conversão do cerrado em pastagem. Em 1994, nova mudança foi observada. O reflorestamento do Ponto 2 foi convertido em cultivo de soja e no Ponto 3 a agricultura foi substituída por pastagem. Finalmente em 1999 configurou-se o uso que predomina até 2010, com a vegetação de Cerrado cobrindo a área do Ponto 1 como vegetação remanescente, o cultivo da soja em rotação com milho, utilizando-se da técnica de plantio direto no Ponto 2 e a presença das pastagens nos Pontos 3 e 4 .

\begin{tabular}{cccc}
\hline Data da Imagem & Pontos & Coordenadas (UTM) & $\begin{array}{c}\text { Uso do Solo } \\
\text { (BRITO, 2001) }\end{array}$ \\
\hline \multirow{2}{*}{1964} & $\mathbf{1}$ & $791.320 \mathrm{E} / 7.889 .989 \mathrm{~N}$ & Cerrado \\
& $\mathbf{2}$ & $794.101 \mathrm{E} / 7.889 .622 \mathrm{~N}$ & Cerrado \\
& $\mathbf{3}$ & $797.027 \mathrm{E} / 7.880 .782 \mathrm{~N}$ & Cerrado \\
& $\mathbf{4}$ & $799.739 \mathrm{E} / 7.873 .718 \mathrm{~N}$ & Cerrado \\
& $\mathbf{1}$ & $791.320 \mathrm{E} / 7.889 .989 \mathrm{~N}$ & Cerrado \\
$\mathbf{1 9 7 9}$ & $\mathbf{2}$ & $794.101 \mathrm{E} / 7.889 .622 \mathrm{~N}$ & Reflorestamento \\
& $\mathbf{3}$ & $797.027 \mathrm{E} / 7.880 .782 \mathrm{~N}$ & Agricultura \\
& $\mathbf{4}$ & $799.739 \mathrm{E} / 7.873 .718 \mathrm{~N}$ & Cerrado \\
& $\mathbf{1}$ & $791.320 \mathrm{E} / 7.889 .989 \mathrm{~N}$ & Cerrado \\
& $\mathbf{2}$ & $794.101 \mathrm{E} / 7.889 .622 \mathrm{~N}$ & Reflorestamento \\
$\mathbf{1 9 8 9}$ & $\mathbf{3}$ & $797.027 \mathrm{E} / 7.880 .782 \mathrm{~N}$ & Agricultura \\
& $\mathbf{4}$ & $799.739 \mathrm{E} / 7.873 .718 \mathrm{~N}$ & Pastagem \\
& $\mathbf{1}$ & $791.320 \mathrm{E} / 7.889 .989 \mathrm{~N}$ & Cerrado \\
& $\mathbf{2}$ & $794.101 \mathrm{E} / 7.889 .622 \mathrm{~N}$ & Agricultura \\
& $\mathbf{3}$ & $797.027 \mathrm{E} / 7.880 .782 \mathrm{~N}$ & Pastagem \\
& $\mathbf{4}$ & $799.739 \mathrm{E} / 7.873 .718 \mathrm{~N}$ & Pastagem \\
& $\mathbf{4}$ & $791.320 \mathrm{E} / 7.889 .989 \mathrm{~N}$ & Cerrado \\
& $\mathbf{1}$ & $794.101 \mathrm{E} / 7.889 .622 \mathrm{~N}$ & Agricultura (plantio direto) \\
& $\mathbf{2}$ & $797.027 \mathrm{E} / 7.880 .782 \mathrm{~N}$ & Pastagem \\
& $\mathbf{3}$ & $799.739 \mathrm{E} / 7.873 .718 \mathrm{~N}$ & Pastagem \\
\hline
\end{tabular}

Fonte: Brito, 2001.

\section{Variações texturais dos solos}

No solo recoberto por Cerrado (Ponto 1), na profundidade de $0-10 \mathrm{~cm}$ o teor médio de areia grossa é de $450 \mathrm{~g} \mathrm{~kg}^{-1}$, de areia fina $250 \mathrm{~g} \mathrm{~kg}^{-1}$, de silte $20 \mathrm{~g} \mathrm{~kg}^{-1}$ e de argila $280 \mathrm{~g}$ $\mathrm{kg}^{-1}$. Na profundidade de $20-30 \mathrm{~cm}$ o teor médio de areia grossa é de $440 \mathrm{~g} \mathrm{~kg}^{-1}$, de areia fina $260 \mathrm{~g} \mathrm{~kg}^{-1}$, de silte $20 \mathrm{~g} \mathrm{~kg}^{-1}$ e de argila $280 \mathrm{~g} \mathrm{~kg}^{-1}$. O solo agrícola (soja rotação com milho - Ponto 2 ) possui constituição relativamente mais argilosa. Entre $0-10 \mathrm{~cm}$ o teor médio de argila é de $720 \mathrm{~g} \mathrm{~kg}^{-1}$, de silte $100 \mathrm{~g} \mathrm{~kg}^{-1}$, de areia grossa $120 \mathrm{~g} \mathrm{~kg}^{-1}$ e de areia fina $60 \mathrm{~g} \mathrm{~kg}^{-1}$. Entre $20-$
$30 \mathrm{~cm}$ o teor médio de argila é de $780 \mathrm{~g} \mathrm{~kg}^{-1}$, de silte $70 \mathrm{~g} \mathrm{~kg}^{-1}$, de areia grossa é de $100 \mathrm{~g}$ $\mathrm{kg}^{-1}$ e $50 \mathrm{~g} \mathrm{~kg}^{-1}$ de areia fina (Tabela 2 ).

Nos solos sob pastagem houve um enriquecimento da fração areia. Na pastagem manejada (Ponto 3) destaca-se a maior concentração de areia fina. O teor médio na profundidade entre $0-10 \mathrm{~cm}$ foi de $460 \mathrm{~g} \mathrm{~kg}^{-1} \mathrm{e}$ entre $20-30 \mathrm{~cm}$ de $450 \mathrm{~g} \mathrm{~kg}^{-1}$. O teor médio da fração areia grossa foi de $310 \mathrm{~g} \mathrm{~kg}^{-1}$ entre 0 $10 \mathrm{~cm}$ e de $310 \mathrm{~g} \mathrm{~kg}^{-1}$ entre $20-30 \mathrm{~cm}$, enquanto a média dos teores de argila foram de $210 \mathrm{~g} \mathrm{~kg}^{-1}$ de $0-10 \mathrm{~cm}$ e $210 \mathrm{~g} \mathrm{~kg}^{-1}$ de $20-$ $30 \mathrm{~cm}$, e a média dos teores de silte foram de 
$20 \mathrm{~g} \mathrm{~kg}^{-1}$ de $0-10 \mathrm{~cm}$ e $30 \mathrm{~g} \mathrm{~kg}^{-1}$ de $20-30 \mathrm{~cm}$. Finalmente o solo com pastagem degradada evidenciou nítida redução nos teores argila se comparado ao solo sob Cerrado, que conseqüentemente, pode afetar a capacidade de estoque de carbono. O teor médio de argila foi de $140 \mathrm{~g} \mathrm{~kg}^{-1}$ na profundidade entre $0-10 \mathrm{~cm}$ e de $160 \mathrm{~g} \mathrm{~kg}^{-1}$ entre $20-30 \mathrm{~cm}$. Os teores médios de areia grossa foram de $450 \mathrm{~g} \mathrm{~kg}^{-1}$ e de $490 \mathrm{~g} \mathrm{~kg}^{-1}$, as profundidades entre $0-10$ e $20-30 \mathrm{~cm}$ respectivamente e de areia fina de $400 \mathrm{~g} \mathrm{~kg}^{-1}$ entre $0-10 \mathrm{~cm}$ e $330 \mathrm{~g} \mathrm{~kg}^{-1}$ entre $20-30 \mathrm{~cm}$, e os teores médios de silte foram de $10 \mathrm{~g} \mathrm{~kg}^{-1}$ de $0-10 \mathrm{~cm}$ e $20 \mathrm{~g} \mathrm{~kg}^{-1}$ de $20-30 \mathrm{~cm}$ (Tabela 2).

Tabela 2: Granulometria, Teor e Natureza da M.O.S. nos solos coletados em função do uso e técnicas de manejo.

\begin{tabular}{|c|c|c|c|c|c|c|c|c|}
\hline \multirow[t]{2}{*}{ Pontos } & \multirow[t]{2}{*}{$\begin{array}{l}\text { Identificação } \\
\text { (Uso Atual) }\end{array}$} & \multirow{2}{*}{$\begin{array}{l}\text { Prof. } \\
* * * \\
(\mathrm{~cm})\end{array}$} & \multicolumn{4}{|c|}{ Granulometria } & \multicolumn{2}{|c|}{$\begin{array}{c}\text { Teor e } \\
\text { Natureza da } \\
\text { M.O.S. } * * * *\end{array}$} \\
\hline & & & $\begin{array}{l}\text { Areia } \\
\text { Grossa } \\
\left(\mathrm{g} \mathrm{kg}^{-1}\right)\end{array}$ & $\begin{array}{c}\text { Areia } \\
\text { Fina } \\
\left(\mathrm{g} \mathrm{kg}^{-1}\right. \\
\quad)\end{array}$ & $\begin{array}{l}\text { Silte } \\
\left(\mathrm{g} \mathrm{kg}^{-1}\right. \\
\quad)\end{array}$ & $\begin{array}{l}\text { Argila } \\
\left(\mathrm{g} \mathrm{kg}^{-1}\right. \\
\quad)\end{array}$ & $\begin{array}{l}\text { C total } \\
\left(\mathrm{g} \mathrm{kg}^{-1}\right. \\
\mathrm{f}\end{array}$ & $\begin{array}{l}\delta^{\mathbf{1 3}} \mathbf{C} \\
(\% 0)\end{array}$ \\
\hline C-1-1 & Cerrado & $0-10$ & 438,1 & 244,7 & 30,0 & 287,2 & 17,4 & $-26,08$ \\
\hline C-1-2 & Cerrado & $20-30$ & 421,5 & 274,1 & 21,2 & 283,2 & 9,2 & $-25,04$ \\
\hline C-2-1 & Cerrado & $0-10$ & 401,8 & 270,6 & 15,2 & 312,4 & 20,1 & $-26,18$ \\
\hline C-2-2 & Cerrado & $20-30$ & 457,0 & 273,8 & 25,6 & 243,6 & 9,0 & $-24,84$ \\
\hline C-3-1 & Cerrado & $0-10$ & 498,1 & 240,7 & 11,6 & 249,6 & 15,0 & $-26,33$ \\
\hline$C-3-2$ & Cerrado & $20-30$ & 437,4 & 244,6 & 18,0 & 300,0 & 7,7 & $-24,44$ \\
\hline $\begin{array}{c}\text { Media } \\
\text { DP * }\end{array}$ & Cerrado & $0-10$ & 446,0 & 252,0 & 18,9 & 283,1 & $\begin{array}{c}17,5 \\
2,6\end{array}$ & $\begin{array}{c}\mathbf{- 2 6 , 2 0} \\
0,13\end{array}$ \\
\hline $\begin{array}{l}\text { Media } \\
\text { DP * }\end{array}$ & Cerrado & $20-30$ & 438,6 & 264,2 & 21,6 & 275,6 & $\begin{array}{l}\mathbf{8 , 6} \\
0,8\end{array}$ & $\begin{array}{c}\mathbf{- 2 4 , 7 7} \\
0,31\end{array}$ \\
\hline S-1-1 & Soja / Milho ** & $0-10$ & 103,0 & 78,2 & 42,4 & 776,4 & 22,8 & $-20,54$ \\
\hline S-1-2 & Soja / Milho ** & $20-30$ & 99,1 & 38,9 & 84,8 & 777,2 & 17,4 & $-18,48$ \\
\hline S-2-1 & Soja / Milho ** & $0-10$ & 128,5 & 83,9 & 124,0 & 663,6 & 23,6 & $-16,66$ \\
\hline$S-2-2$ & Soja / Milho ** & $20-30$ & 103,3 & 32,3 & 75,2 & 789,2 & 15,4 & $-14,81$ \\
\hline$s-3-1$ & Soja / Milho ** & $0-10$ & 115,2 & 31,8 & 131,0 & 722,0 & 20,6 & $-17,43$ \\
\hline$s-3-2$ & Soja / Milho ** & $20-30$ & 110,5 & 62,7 & 53,6 & 773,2 & 16,5 & $-16,13$ \\
\hline $\begin{array}{l}\text { Media } \\
\text { DP * }\end{array}$ & Soja / Milho ** & $0-10$ & 115,6 & 64,6 & 99,1 & 720,7 & $\begin{array}{c}22,3 \\
1,5\end{array}$ & $\begin{array}{c}\mathbf{- 1 8 , 2 1} \\
2,06\end{array}$ \\
\hline $\begin{array}{c}\text { Media } \\
\text { DP * }\end{array}$ & Soja / Milho ** & $20-30$ & 104,3 & 44,6 & 71,2 & 779,9 & $\begin{array}{c}16,4 \\
1,0 \\
\end{array}$ & $\begin{array}{c}-16,47 \\
1,86 \\
\end{array}$ \\
\hline PM-1-1 & Pastagem Manejada & $0-10$ & 316,8 & 441,4 & 21,0 & 220,8 & 9,1 & $-13,34$ \\
\hline PM-1-2 & Pastagem Manejada & $20-30$ & 299,5 & 447,1 & 29,0 & 224,4 & 6,9 & $-13,05$ \\
\hline PM-2-1 & Pastagem Manejada & $0-10$ & 304,3 & 451,7 & 26,0 & 218,0 & 10,6 & $-13,36$ \\
\hline PM-2-2 & Pastagem Manejada & $20-30$ & 310,8 & 465,2 & 26,0 & 198,0 & 6,7 & $-13,17$ \\
\hline PM-3-1 & Pastagem Manejada & $0-10$ & 298,3 & 481,7 & 23,6 & 196,4 & 14,3 & $-13,39$ \\
\hline PM-3-2 & Pastagem Manejada & $20-30$ & 305,2 & 434,0 & 47,2 & 213,6 & 7,5 & $-12,85$ \\
\hline $\begin{array}{c}\text { Media } \\
\text { DP * }\end{array}$ & $\begin{array}{l}\text { Pastagem } \\
\text { Manejada }\end{array}$ & $0-10$ & 306,5 & 458,3 & 23,5 & 211,7 & $\begin{array}{c}11,3 \\
2,7\end{array}$ & $\begin{array}{c}\mathbf{- 1 3 , 3 7} \\
0,03\end{array}$ \\
\hline $\begin{array}{c}\text { Media } \\
\text { DP } *\end{array}$ & $\begin{array}{l}\text { Pastagem } \\
\text { Manejada }\end{array}$ & $20-30$ & 305,2 & 448,8 & 34,1 & 212,0 & $\begin{array}{l}7,0 \\
0,4\end{array}$ & $\begin{array}{c}-\mathbf{1 3}, \mathbf{0 3} \\
0,16 \\
\end{array}$ \\
\hline PD-1-1 & Pastagem Degradada & $0-10$ & 437,5 & 414,5 & 11,2 & 136,8 & 6,3 & $-13,93$ \\
\hline PD-1-2 & $\begin{array}{l}\text { Pastagem } \\
\text { Degradada }\end{array}$ & $20-30$ & 483,7 & 344,7 & 8,0 & 163,6 & 4,5 & $-14,62$ \\
\hline PD-2-1 & $\begin{array}{l}\text { Pastagem } \\
\text { Degradada }\end{array}$ & $0-10$ & 447,6 & 407,6 & 3,2 & 141,6 & 6,1 & $-13,96$ \\
\hline PD-2-2 & $\begin{array}{l}\text { Pastagem } \\
\text { Degradada }\end{array}$ & $20-30$ & 508,4 & 324,4 & 18,8 & 148,4 & 4,1 & $-14,38$ \\
\hline PD-3-1 & $\begin{array}{l}\text { Pastagem } \\
\text { Degradada }\end{array}$ & $0-10$ & 459,3 & 393,5 & 1,6 & 145,6 & 6,6 & $-14,57$ \\
\hline PD-3-2 & $\begin{array}{l}\text { Pastagem } \\
\text { Degradada }\end{array}$ & $20-30$ & 483,8 & 330,4 & 15,0 & 170,8 & 4,4 & $-13,50$ \\
\hline $\begin{array}{c}\text { Media } \\
\text { DP * }\end{array}$ & $\begin{array}{l}\text { Pastagem } \\
\text { Degradada }\end{array}$ & $0-10$ & 448,1 & 405,2 & 5,3 & 141,3 & $\begin{array}{l}6,4 \\
0,3\end{array}$ & $\begin{array}{c}\mathbf{- 1 4 , 1 5} \\
0,36\end{array}$ \\
\hline Media & Pastagem & $20-30$ & 491,9 & 333,2 & 13,9 & 160,9 & 4,3 & $-14,17$ \\
\hline
\end{tabular}


* Desvio Padrão; ** Soja rotação com Milho; *** Profundidade; **** Matéria Orgânica do Solo.

\section{Teor e origem da M.O.S}

Sob vegetação original de Cerrado arbóreo, na profundidade entre $0-10 \mathrm{~cm}$ foram encontrados teores de carbono (Ctotal) de 15 a $20 \mathrm{~g} \mathrm{~kg}^{-1}$ (média de $17,5 \mathrm{~g} \mathrm{~kg}^{-1}$; dp de $2,6)$ e na profundidade entre $20-30 \mathrm{~cm}$ teores de 7,7 a $9,2 \mathrm{~g} \mathrm{~kg}^{-1}$ (média de $8,6 \mathrm{~g} \mathrm{~kg}^{-1} ; \mathrm{dp}$ $0,8)$. No solo recoberto com pastagem manejada, entre $0-10 \mathrm{~cm}$, Ctotal variou entre 9,1 e $14,3 \mathrm{~g} \mathrm{~kg}^{-1}$ (média de $11,3 \mathrm{~g} \mathrm{~kg}{ }^{-1} ; \mathrm{dp}$ $2,7)$ e entre $20-30 \mathrm{~cm}$ Ctotal variou de 6,7 a $7,5 \mathrm{~g} \mathrm{~kg}^{-1}$ (média de $7,0 \mathrm{~g} \mathrm{~kg}^{-1}$; dp 0,4). A perda média aproximada de carbono nas camadas de solo de pastagem manejada em relação às camadas do solo do cerrado foi de aproximadamente $22 \%$ nos primeiros $10 \mathrm{~cm}$ de profundidade e de $19 \%$ entre 20 a $30 \mathrm{~cm}$. No solo com pastagem degradada houve nitidamente um empobrecimento de $\mathrm{C}$ tanto em superfície quanto em subsuperfície (63,43\% e 50\%, respectivamente). $\mathrm{Na}$ profundidade entre $0-10 \mathrm{~cm}$ os teores de $C$ variaram de 6,1 a $6,6 \mathrm{~g} \mathrm{~kg}^{-1}$ (média de $6,4 \mathrm{~g}$ $\left.\mathrm{kg}^{-1} ; \mathrm{dp} 0,3\right)$ e, entre $20-30 \mathrm{~cm}$ variaram de 4,1 a $4,5 \mathrm{~g} \mathrm{~kg}^{-1}$ (média de $4,3 \mathrm{~g} \mathrm{~kg}^{-1} ; \mathrm{dp} \mathrm{0,2).}$ No solo cultivado com soja, os teores de $C$ na superfície, entre $0-10 \mathrm{~cm}$, variaram de 20,6 a $23,6 \mathrm{~g} \mathrm{~kg}^{-1}$ (média de $22,3 \mathrm{~g} \mathrm{~kg}^{-1}$; dp 1,5 ) e, entre $20-30 \mathrm{~cm}$, de 15,4 a $17,4 \mathrm{~g} \mathrm{~kg}^{-1}$ (média de $16,4 \mathrm{~g} \mathrm{~kg}^{-1} ; \mathrm{dp} \mathrm{1,0)}$ (Tabela 2).

Quando comparados os teores de C fixados nos solos sob diferentes categorias de uso com o solo recoberto pela vegetação nativa de cerrado arbóreo, determinou-se que o solo cultivado com soja em rotação com milho após 10 anos de manejo em sistema de plantio direto foi o sistema mais eficiente em aumentar a concentração total de carbono. Tal resultado encontra sustentação no conhecimento adquirido de que o plantio direto é o sistema de manejo do solo adequada para promover o aporte de material orgânico proveniente de resíduos vegetais e a proteção da superfície do solo (CAMPOS et al., 1995). Por ser considerada também um sistema adequado para minimizar a quebra das pedoestruturas, pode resultar em significante aumento de $\mathrm{C}$ no solo e diminuição das emissões de $\mathrm{CO}_{2}$ para a atmosfera (LAL, 2006).

Nesta área, o enriquecimento em $C$ ocorreu na superfície e em subsuperfície, superando os teores determinados no solo do Cerrado. A conservação ou aumento do teor de $C$ pode ser explicado pelo menor revolvimento do solo, da incorporação de parte dos resíduos vegetais da cultura inibindo a emissão de $\mathrm{CO}_{2}$, a diminuição do selamento superficial do solo que resulta em aumento da infiltração e redução da erosão e conservação da pedoestrutura (SÁ et al., 2001; SIX et al., 2002; CERRI et al., 2007). De acordo com Carvalho et al. (2009) quando o sistema de plantio direto associa rotação de mais de uma cultura por ano e a aplicação de fertilizantes há incremento de resíduos e nutrientes, entre eles o $C$, porém ressaltam que a relação direta entre o sistema de plantio direto e o aumento da taxa de acúmulo de $\mathrm{C}$ é ainda inconclusiva. Alguns autores (FREITAS et al., 2000; ROSCOE; BUURMAN, 2003; BAYER et al., 2006) reportaram mínimas variações nas concentrações da MOS sob sistema de plantio direto uma vez outros fatores foram limitantes como a textura, mineralogia e dificuldade de adição de $\mathrm{C}$ durante o período seco.

A área cultivada com soja em rotação com milho sob sistema de plantio direto encontra-se sob solo relativamente mais argiloso (70\% em superfície e 78\% em subsuperfície). Por se tratar de um solo de composição laterítica constituído por argila de 
atividade baixa (LAC), o aumento da MOS pode resultar da relação entre carbono e argila, sendo que esta relação equaliza os teores obtidos em solos cultivados com aqueles obtidos em vegetação nativa (FELLER et al., 1991). Além da caolinita, as elevadas concentrações de óxido de ferro nos solos lateríticos do Cerrado propiciam as ligações de troca entre os íons férricos e as superfícies dos grupos funcionais da matéria orgânica, ligações estas que interferem na decomposição da matéria orgânica e redução da biodisponibilidade (OADES et al., 1989; BALESDENT et al., 2000; BAYER et al., 2006). Mineralogia e textura estão relacionadas aos gradientes de teor de MOS (BROWN; LUGO, 1982; FELLER; BEARE, 1997; KRULL; SKJEMSTAD, 2003) e respondem pela conservação do $\mathrm{C}$ e pelo fracionamento isotópico.

Considerando a relação uso do solo e perda de $\mathrm{C}$, os menores teores de $\mathrm{C}$ ocorreram na pastagem degradada nas duas profundidades analisadas. As pastagens degradadas do bioma Cerrado formadas após o corte e a queima da vegetação original são de baixa quantidade e qualidade não recobrindo toda a superfície do solo. Os contrastes climáticos sazonais com chuvas concentradas e forte insolação e dessecação tornam os solos expostos altamente susceptíveis, resultando em perda de estrutura, aumento dos processos erosivos e a perda da fertilidade física e química que refletem diretamente nos teores de $C$ (BROSSARD; LÓPES-HERNÁNDES， 2005). Além do manejo não adequado, a textura novamente reflete no resultado do $\mathrm{C}$. O solo da pastagem degradada apresentou elevados teores de areias grossa e fina (83\% nos horizontes superficial e subsuperficial) e o não desenvolvimento da macroestrutura são fatores que contribuíram para a diminuição do teor de C. É conhecido que parte da MOS está protegida nos macroagregados, em uma taxa de $10 \%$ em solos cultivados e $19 \%$ em solos não cultivados segundo Beare et al. (1994). Esta capacidade se eleva com o aumento do teor de argila e ausência de cultivo assim como com a freqüência na qual os agregados são susceptíveis à destruição in situ pelo cultivo ou ainda em relação à sua intrínseca estabilidade em água (BALESDENT et al., 2000).

Quando os solos do Cerrado são convertidos em sistemas agrícolas sem manejo adequado, a degradação macroestrutural é rapidamente verificada, pois são originalmente frágeis e pouco desenvolvidos (BALBINO et al., 2002). A micro e a macroestrutura dos solos são reconhecidamente as unidades que controlam a dinâmica da MOS, pois nestas unidades desenvolve-se o processo de proteção física da MOS contra a biodegradação (OADES, 1995; SKENE et al., 1996; ANGERS; CHENU, 1997, FELLER; BEARE, 1997; BALESDENT et al., 2000). Em vários ecossistemas e, especialmente nos agroecossistemas a formação e a destruição dos macroagregados que acompanham a variação da dinâmica sazonal ocorrem em um ritmo mais rápido do que a entrada de um novo $C$ proveniente da cultura (PLANTE et al., 2002; SIX et al., 2004).

$\mathrm{Na}$ área de estudo, o empobrecimento de $C$ nos primeiros $30 \mathrm{~cm}$ do solo parece refletir o que Balesdent et al. (2000) denominaram como as três maiores ações que comandam a dinâmica da MOS: mudanças microclimáticas do solo, incorporporação da MOS na matriz do solo e periódica quebra da estruturas pedológicas. Desta forma, nesta área de pastagem degradada a estabilização da MOS fica comprometida pelo tipo de solo e pela susceptibilidade as condições sazonais. Finalmente quando se comparam os dois 
tipos de pastagem, manejada e degradada, determinou-se empobrecimento menos acentuado no solo da pastagem manejada em relação ao solo sob vegetação original de Cerrado e maior incorporação de $\mathrm{C}$ quando comparado com a pastagem degradada.

Em relação à origem do carbono, o enriquecimento ou empobrecimento no solo está acompanhado de mudanças da assinatura isotópica $\left(\delta^{13} \mathrm{C}\right)$. Amparados no fato de que a história vegetativa da área de estudo é bem conhecida, as mudanças na assinatura $\delta^{13} \mathrm{C}$ da matéria orgânica originada de diferentes tipos de vegetação $\left(C_{3}\right.$ e $\left.C_{4}\right)$ foram usadas para descrever a perda do $\mathrm{C}$ da vegetação nativa e a acumulação de C derivado da nova vegetação assim como proposto por Cerri et al. (1985) \& Feller \& Beare (1997). A vegetação do Cerrado brasileiro é composta predominantemente por espécies arbóreas $\mathrm{C}_{3}$ e gramíneas $\mathrm{C}_{4}$. $\mathrm{Na}$ área de estudo, a MOS da área recoberta por Cerrado apresentou $\delta^{13} \mathrm{C}$ entre -26,08 e $26,33 \%$ na profundidade entre $0-10 \mathrm{~cm}$ (média de $-26,20 \%$, dp. 0,13) e entre 24,44 e -25,04\%o entre 20-30cm (média de $24,77 \%$, dp. 0,31). Os valores obtidos estão de acordo com aqueles determinados para as espécies arbóreas típicas do Cerrado com assinatura isotópica de $-27,76 \%$ e, localmente, podem coexistir com espécies arbóreas da floresta úmida que possui assinatura isotópica de $-28,44 \%$ o (HOFFMANN et al., 2005) (Tabela 2).

$\mathrm{O} \delta^{13} \mathrm{C}$ da matéria orgânica dos solos atualmente usados com pastagem manejada, pastagem degradada e soja e milho diferem daqueles determinados sob Cerrado e indicam clara tendência de alteração da decomposição e incorporação da MOS nas áreas convertidas. Houve mudança nítida de incorporação de plantas $\mathrm{C}_{4}$ originadas da gramínea forrageira Brachiaria spp. no solo convertido em pastagem manejada (15 anos de conversão) que apresentou $\delta^{13} \mathrm{C}$ entre 12,85 a $-13,39 \%$ (média de $-13,37 \%$ entre $0-10 \mathrm{~cm}$ e de $-13,03 \%$ entre $20-30 \mathrm{~cm}$ de profundidade). Assinatura isotópica similar foi determinada no solo com pastagem degradada (40 anos de conversão) que apresentou $\delta^{13} \mathrm{C}$ entre $-13,50$ e $-14,62 \%$ o (média de $-14,15 \%$ entre $0-10 \mathrm{~cm}$ e de $14,17 \%$ entre $20-30 \mathrm{~cm}$ de profundidade). Na área cultivada com soja e milho (10 nos de conversão com sistema de plantio direto) foi determinada assinatura isotópica que indica mistura de vegetação resultante da incorporação no solo de raízes e resíduos de soja $\left(C_{3}\right)$ e milho $\left(C_{4}\right)$. Os valores mínimos e máximos obtidos nas profundidades entre 010 e $20-30 \mathrm{~cm}$ foram, respectivamente, 14,81 e -20,54\%o (a média obtida nas profundidades entre $0-10 \mathrm{~cm}$ foi de $-18,21 \%$ o e entre $20-30 \mathrm{~cm}$ de $-16,47 \%$ ). Os resultados indicaram que após 15 e 40 anos de conversão do cerrado arbóreo em pastagens resultaram em modificações relacionadas ao decréscimo do teor e a substituição do $\mathrm{C}$ derivado MOS de espécies arbóreas $C_{3}$ pelo $C$ da MOS derivado de gramíneas $\mathrm{C}_{4}$ cultivadas ou não. A conversão em área agrícola não foi acompanhada por diminuição da taxa de carbono, mas na qualidade da MOS (Tabela 2).

\section{CONSIDERAÇÕES FINAIS}

Sob vegetação natural de Cerrado, - solo acumulou carbono orgânico em quantidade satisfatória, equiparável ao sistema de manejo em plantio direto. A conversão do Cerrado para pastagem mesmo sendo esta de Brachiaria de elevada relação $\mathrm{C} / \mathrm{N}$ alterou tanto o fluxo quanto a natureza resultando em impactos na qualidade do solo.

O desmatamento e o uso / manejo inadequado do solo interrompe a deposição da serrapilheira, aumenta a decomposição da 
matéria orgânica estocada no solo com perda da fertilidade física, com aumento na emissão de $\mathrm{CO}_{2}$ e outros gases para a atmosfera.

Os resultados desta pesquisa em solos originalmente recobertos por Cerrado mostraram transformações no teor do carbono orgânico do solo em função da mudança de uso, manejo e textura. A conversão das áreas sob vegetação de Cerrado em pastagens manejada (15 anos de uso) e degradada (40 anos de uso) resultaram numa diminuição do teor de carbono (Ctotal). Na área de plantio de soja rotação com milho sob sistema de plantio direto, houve um enriquecimento $\mathrm{da}$ incorporação do $C$ em superfície e subsuperfície. Além do manejo, a textura e a mineralogia dos solos influenciaram a dinâmica do $C$, visto que solos mais argilosos, sob sistema de plantio direto, apresentaram maior teor de $\mathrm{C}$.

Os resultados obtidos neste artigo sugerem a dinâmica do $\mathrm{C} \%$ do solo quando os ecossistemas naturais são convertidos em sistemas agrícolas, porém, confirmaram a necessidade de considerar a diversidade dos solos e os usos e as técnicas de manejo dos solos agrícolas no Bioma Cerrado a fim de avaliar a dinâmica do carbono orgânico do solo e seus reflexos na conservação ambiental. 


\section{REFERÊNCIAS BIBLIOGRÁFICAS}

ANGERS, D. A.; CHENU, C. Dynamics of soil aggregation and $C$ sequestration. In: $L A L$, R.; KIMBLE, J.; FOLLET, R. F.; STEWART, B. A. (Eds.). Soil Processes and the Carbon Cycle. Boca Raton, FL: CRC Press, 1997, p.199-206.

BALBINO, L. C.; BROSSARD, M.; LEPRUN, J. C.; BRUAND, A. Mise en valeur des Ferralsols de la région du Cerrado (Brésil) et évolution de leurs propriétés physiques: une étude bibliographique, Étude et gestion des sols, v.9, p.83-104, 2002.

BALESDENT, J.; CHENU, C.; BALABANE, B. Relationship of soil organic matter dynamics to physical protection and tillage. Soil \& Tillage Research, v.53, p.215-230, 2000.

BAYER, C.; MARTIN-NETO, L.; MIELNICZUK, J.; PAVINATO, A.; DIECKOW, J. Carbon sequestration in two Brazilian Cerrado soils under no-till. Soil \& Tillage Research, v.86, p.237-245, 2006.

BEARE, M. H.; CABRERA, M. L.; HENDRIX, P. F.; COLEMAN, D. C. Aggregate-protected and unprotected organic matter pools in conventional-tillage and no-tillage soils. Soil Sci. Soc. Am. J., v.58, p.787-795, 1994.

BERNOUX, M.; CARVALHO, M. C. S.; VOLKOFF, B.; CERRI, C. C. Brazil's soil carbon stocks. Soil Science Society American Journal, v.66, p.88-896, 2002.

BRITO, J. L. S. Adequação das potencialidades do uso da terra na Bacia do ribeirão Bom Jardim no Triângulo Mineiro (MG): Ensaio de Geoprocessamento. São Paulo: USP/FFLCH, 2001, 184 p.

BROSSARD, M.; LÓPEZ-HERNÁNDEZ, D. Des indicateurs d'évolution du milieu et des sols pour render durable I'usage des savanes d'Amérique du Sud. Natures Sciences Sociétés, v.13, p.266-278, 2005.

BROWN, S.; LUGO, A. E. The storage and production of organic matter in tropical forests and their role in the global carbon cycle. Biotropica, v.14, p.161-187, 1982.

CARVALHO, J. L. N.; CERRI, C. E. P.; FEIGL, B. J.; PICCOLO, M. C.; GODINHO, V. P.; HERPIN, U.; CERRI, C. C. Conversion of Cerrado into Agricultural Land in the SouthWestern Amazon: Carbon Stocks and Soil Fertility. Sci. Agric., v.66 (2), p.233-241, 2009.

CERRI， C.; FELLER， C.; BALESDENT， J.; VICTORIA, R.; PLENECASSEGNE, A.
Application du traçage isotopique naturel en ${ }^{13} \mathrm{C}$, à l'étude de la dynamique de la matière organique dans les sols. C.R. Acad. Sci. Paris, v.11 (9), p.423-428, 1985.

CERRI, C. E. P.; COLEMAN, K.; JENKINSON, D. S.; BERNOUX, M.; VICTORIA, R.; CERRI, C. C. Modeling soil carbon from forest and pasture ecosystems of Amazon, Brazil. Soil Sci. Soc. Am. J., v.67, p.1879-1887, 2003.

CERRI, C. E. P.; SPAROVEK, G.; BERNOUX, M.; EASTERLING, W. E.; MELILLO, J. M.; CERRI, C. C. Tropical agriculture and global warming: impacts and mitigation options. Sci. Agri., v.64 (1), p.83-99, 2007.

CURI, N.; FRANZMEIER, D. P. Toposequence of oxisols from the Central Plateau of Brazil. Soil Science Society of America Journal, v.48 (2), p.341-346, 1984.

DA SILVA, J. E.; LEMAINSKI, J.; RESCK, D. V. S. Perdas de matéria orgânica e suas relações com a capacidade de troca catiônica em solos da região de Cerrados do oeste Baiano. Rev. Bras. Cienc. Solo, v.18, p.541547, 1994.

DA SILVA, J. E.; RESCK, D. V. S.; CORAZZA, E. J.; VIVALDI, L. Carbon storage in clayey Oxisol cultivated pastures in the "Cerrado" region, Brazil. Agriculture, Ecosystems and Environment, v.103, p.357-363, 2004.

EGOH, B.; REYERS, B.; ROUGET, M.; BODE, M.; RICHARDSON, D. M. Spatial congruence between biodiversity and ecosystem services in South Africa. Biol. Conserv., v.142, p.553562, 2009.

DEINES, P. The isotopic composition of reduced organic carbon. In: FRITZ, P.; FONTES, J. C. (Eds.). Handbook of Environmental Isotope Geochemistry, Elsevier, Amsterdam, v.1, 1980, p.329-406.

EMPRESA BRASILEIRA DE PESQUISA AGROPECUÁRIA - EMBRAPA. Manual de métodos de análise de solo. 2.ed. Rio de Janeiro, Centro Nacional de Pesquisa de Solos, 1997. 212p.

FELLER, C.; FRITSCH, E.; POSS, R.; VALENTIN, C. Effects de la texture sur le stockage et la dynamique des matières organiquess quelques sols ferrugineux et ferralitiques (Afrique de l'Ouest, en particulier). Cah. ORSTOM, sér. Pédologie, v.26, p.25-36, 1991. 
FELLER, C.; BEARE, M. H. Physical control of soil organic matter dynamics in the tropics. Geoderma, v.79, p.69-116, 1997.

FREITAS, P. L.; BLANCANEAUX, P.; GAVINELLI， E.; LARRÉ-LARROUY, M. C.; FELLER, C. Nível e natureza do estoque orgânico de latossolos sob diferentes sistemas de uso e manejo. Pesq. Agropec. Bras., v.35, p.157-170, 2000.

HOFFMANN, W. A.; FRANCO, A. C.; MOREIRA, M. Z.; HARIDASAN, M. Specific leaf area explains differences in leaf treats between congeneric savanna and forest trees. Functional Ecology, v.19, p.932-940, 2005.

JANTÁLIA, C. P.; RESCK, D. V. S.; ALVES, B. J. R.; ZOTARELLI, L.; URQUIAGA, S.; BODDEY, R. M. Tillage effect on C stocks of a clayey Oxisol under a soybean-based crop rotation in the Brazilian Cerrado region. Soil Till. Res., v.95, p.97-109, 2007.

JEPSON, W. A disappearing bioma? Reconsidering land-use cover change in the Brazilian savanna. The Geographical Journal, v.171 (2), p.99-111, 2005.

KLINK, C. A.; MACHADO, R. B. Conservation of brazilian cerrado. Conservation Biology, v.19, p.707-713, 2005.

KRULL, E.; SKJEMSTAD, J. O. $\delta^{13} \mathrm{C}$ and $\delta^{15} \mathrm{~N}$ profiles in ${ }^{14} \mathrm{C}$-dated Oxisol and Vertisols as a function of soil chemistry and mineralogy. Geoderma, v.112, p.1-29, 2003.

LAL, R. Soil carbon dynamic in cropland and rangeland. Environmental Pollution, v.116, p.353-362, 2002.

LAL, R. Global potential of carbon sequestration to mitigate the greenhouse effect. Critical Reviews in Plant Sciences, Boca Raton, v. 22, n. 2, p. 151-184, 2003.

LAL, R. Enhancing crop yields in the developing countries through restoration of the soil organic carbon pool in agricultural lands. Land Degradation and Development, v.17, p.197-209, 2006.

LOPES, A. S. Soils under Cerrado: a success story in soil management. Better Crops Int., v.10, p.9-15, 1996.

MACEDO J.; BRYANT R. B. Morphology, Mineralogy, and Genesis of a hydrosequence of Oxisols in Brazil. Soil Science Society of America Journal, v.51, p.690-698, 1987.

MARCHÃO, R. L.; BECQUER, T.; BRUNET, D.; BALBINO, L. C.; VILELA, L.; BROSSARD, M. Carbon and nitrogen stocks in a Brazilian clayey Oxisol: 13-year effects of integrated crop-livestock management systems. Soil Till. Res., v.103, p.442-450, 2009.

MINISTÉRIO DO MEIO AMBIENTE - MMA. Projeto de Monitoramento do Desmatamento nos Biomas Brasileiros por Satélite. Disponível em: <www.mma.org.br/ sitio/index.php?ido $=$ conteudo. monta\&idEstrut ura $=201$ \&idConteudo $=8448 \&$ \&dMenu $=8982>$. Acessado em: Abril, 2010.

OADES, J. M.; GILLMAN, G. P.; UEHARA, G. Interactions of soil organic matter and variable-charge clays. In: COLEMAN, D. C.; OADES, J. M.; UEHARA, G. (Eds.). Dynamics of Soil Organic Matter in Tropical Ecosystems. Honolulu: Hawaii Press, 1989, p.69-95.

OADES, J. M. An overview of processes affecting the cycling of organic carbon in soils. In: ZEPP, R. G.; SONNTAG, C. (Eds.). The Role of Non-Living Organic Matter in the Earth's Carbon Cycle. Wiley, New York: Dahlem Workshop Reports, 1995, p.293-303.

PLANTE, A. F.; FENG, Y.; MCGILL, W. B. A modeling approach to quantifying soil macroaggregate dynamics. Can. J. Soil Sci., v.82, p.181-190, 2002.

REATTO, A.; CORREIA, J. R.; SPERA, S. T.; MARTINS, E. S. Solos do Bioma Cerrado: aspectos pedológicos. In: SANO, S. M.; ALMEIDA, S. P. D; RIBEIRO, J. F. (Eds.). Cerrado - Ecologia e Flora. Brasília, DF: Embrapa Informação Tecnológica, v.1, 2008, p.107-133.

ROSA, R., LIMA, S. C.; ASSUNÇÃO, W. L. Abordagem preliminar das condições climáticas de Uberlândia-MG. Sociedade \& Natureza, v.3 (5 e 6), p.91-108, 1991.

ROSCOE, R.; BUURMAN, P. Tillage effects on soil organic matter in density fractions of a Cerrado Oxisol. Soil Till. Res., v.104, p.185202, 2003.

SÁ, J. C. M.; CERRI, C. C.; LAL, R.; DICK, W. A.; VENZKE FILHO, S.; PICCOLO, M. C.; FEIGL, B. Organic matter dynamics and carbon sequestration rates for a tillage chronosequence in a Brazilian Oxisol. Soil Science Society of America Journal, v.65, p.1486-1499, 2001.

SAVIDAN, Y.; JANK, J. DE; SOUZA, F. H. D.; BOOK, A. Preliminary evaluation of Panicum maximum germplasm in Brazil. In: International agronomy research program. Proc. XVth. Int. Grassl. Congress, Kyoto, Japan, 1985, p.117-118.

SILVA, F. A. M.; ASSAD, E. D.; EVANGELISTA, B. A. Caracterização climática do Bioma Cerrado. In: SANO, S. M.; 
ALMEIDA, S. P. DE; RIBEIRO, J. F. (Eds.). Cerrado - Ecologia e Flora. Brasília, DF: Embrapa Informação Tecnológica, v.1, 2008, p. 69-106.

SIX, J.; FELLER, C.; DENEF, K.; OGLE, S. M.; SA, J. C. M.; ALBRECHT, A. Soil organic matter, biota and aggregation in temperate and tropical soils effects of no-tillage. Agronomie, v.22, p.755-775, 2002.

SIX, J.; BOSSUYT, H.; DEGRYSE, S.; DENEF, $\mathrm{K}$. A history of research of the link between (micro) aggregates, soil biota, and soil organic matter dynamics. Soil \& Tillage Research, v.79, p.7-31, 2004.
SKENE, T. M.; SKJEMSTAD, J. O.; OADES, J. M.; CLARKE, P. J. The influence of inorganic matrices on the decompositions of straw. Aust. J. Soil Res., v.34, p.413-426, 1996.

VOLKOFF, B. Organisations régionales de la couverture pédologique du Brésil. Chronologie des différenciations. Cah. Orstom, sér. Pédologie, v.XXI, p.225-236, 1985.

WANIEZ, P. Les Cerrados, un "espace frontière" brésilien. G.I.P. RECLUSORSTOM, Montpellier, 1992, 344 p. 